The Up-to-the-Minute Laundry

By Charles W. Geiger

THE visiting delegates to The National Laundry Convention recently held in San Francisco, came at a time when there had been developed in that city one of the model laundries of the world. In point of size, hygiene and sanitary arrangements, light and air provision, efficiency of staff provision, efficiency of staff prganization, economy of plant operation, and for the
general contentment of the general contentment of the
workers and welfare work this laundry is without a peer in the world.

The main building is 275 feet square. It is divided into two immense rooms by a fire wall. All the washing enters at the extreme left of the building, and is discharged ready for the home on the right. The bundles are taken to the marking and sorting departments, and then to the various wash wheels, different washwheels being provided for different kinds of goods.

ferent kinds of goods.
From the time the laundry is brought to the door From the time the laundry is brought to the door
of the plant by the driver until it is returned to him for delivery to the owner, the garments are handled almost entirely by labor-saving devices. Every unnecessary operation in the handling of the various garments is eliminated by equipment that has recently been installed at a cost of $\$ 150,000$.

This laundry uses about 400,000 gallons of water a day, secured from its own artesian wells on the premises. It also ust $,+1,4$ 000 punds of 1 t 500 , week which is thet special plant, so situgtect livered to each batto of

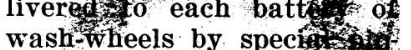
wash-wheels by spectwity
ing. The wash-wheels the ing. The wash-wheels the selves have been installed with a device that at a predetermined time, opens the outlet dive in the washwhees ond then rings a bell after to machine has been drained and makes a record showing accurately eactop-

eration of every load washedfand shows the number of working hours each wash machine proficest $\mathrm{By}$ this method $x_{3}$ e man can take care of an entiresattery of washing inachines.

The ter for washing purpeses is softened in a specian constructed water ofot ther which is placed at such $a$ height that the water is delivered into seven

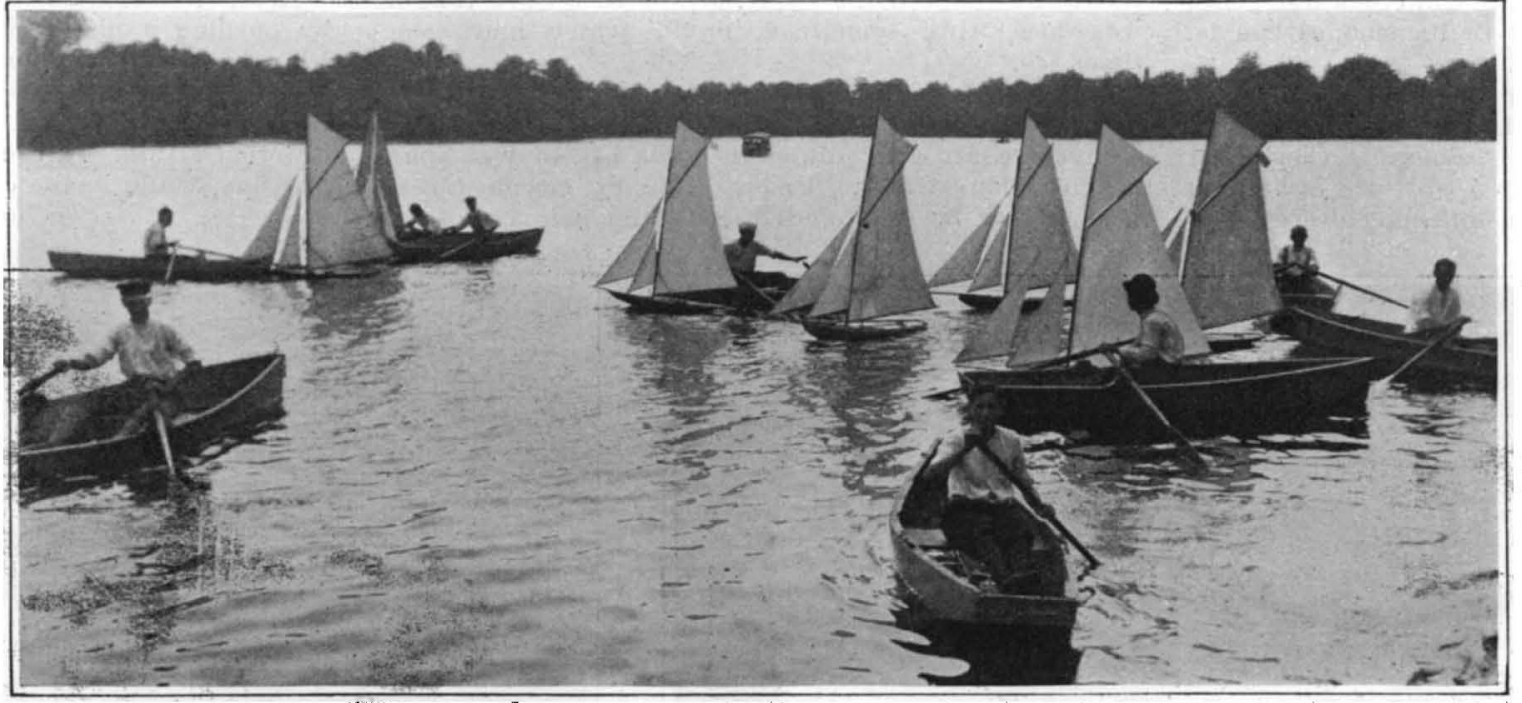

Wokeying for position at the start of a model yacht race
Racing with Model Yachts

By William Henry

THE universal interest in 1 yachting which has been aroused by the International Cup Races, has been extended to the races of the model yachts, which vie creditably in gracefulness with their larger rivals.

In Brooklyn, N. Y., there is a flourishing gathering of yachting enthusiasts, called the Prospect Park Model Yacht Club, composed of about 30 members, with a beautiful club house built on the shores of the large lake in Prospect Park. This house, built of rustic woodwork, while being the headquarters of the club, is also used to house the large collection of model yachts and schooners owned by members of the association. As it is situated on the banks of the lake, it is a 20,000-gallon storage tanks (located on the roof of the reinformed concrete and brick power plant) by gravity. From these seven tanks the softened water is delivered by gravity for use in the washing machines.

Every machine in the laundry is operated by electric Every machine in the laundry is operated by electric
motors, current for which is generated in a power

bundling facilities, out of the cradle, and gently place it in the water, jump into a rowboat and pull out on the lake for a spin. Racing with model yachts differs from regular yacht races in that the owner follows his yacht in a rowboat, and when he wishes to change tack, rows to leeward or behind and swings the mainsail around by hand, starting it on its new course. Each time he touches the yacht, five seconds' penalty is added to the elapsed time. The rudder is connected to the mainsheet by a small cord and the tiller swings between two small nuts, which can be very quickly adjusted to the required position. In running before the wind the main sheet is connected in such a way that the tiller is held at the proper angle to sail a true course. In beating and reaching, the rudfer is left free, following the keel of the boat.

Races of the Prospect Park Node Yacht Club are held on Saturday afternoons at 3 o'clock and on Sunday mornings at 10 o'clock, all the rules of yacht racing teing strictly observed.

house with two powerful steam-driven generators. A novel feature in connection with these steam-driven generators is the fact that the water from the artesian wells is pumped through the condensers, which not only cools the condensers but also partly heats the water, which is then more effectively dealt with by the water softener.

In racing these model boats, they are divided into four classes, as follows: 1stelass over 48 and under 54 inches load water line; 2 nód class over 42 and under 48 inches load water line; 3 rd class over 36 and under $4 \dot{2}$ inches load water line; Schooner class, minimum load water line 36 inches, no maximum.

(Continued on page 519 )

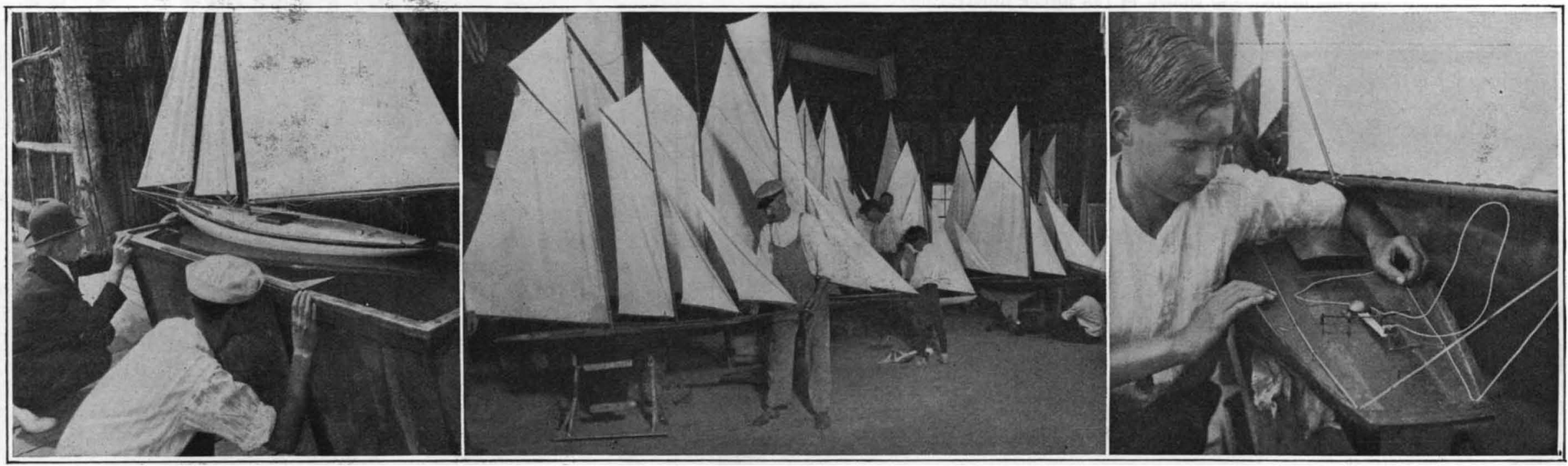

Left: The club captain and assistant measuring one of the yachts. Center: Busy yachtsmen in the clubhouse preparing their yachts for the races. Right: Youthful yacht owner adjusting tiller

of his yacht for a beat to windward

With the model yacht enthusiasts of Prospect Park, Brooklyn 
tempt to enforce this. In many more the nuisance has got to such a point that it has been necessary to institute recognized public parking plots. Those who attend the ball games in New York knòw perhaps the most extensive of these-we have seen half a mile of the Speedway curb banked solid with cars, backed in as close together as the prohibition against two space would permit. But in the more crowded sections of New York and other cities there are no extensive curb areas available for parking in this fashion. It is therefore necessary to utilize to the utmost whatever of open space there may be at hand. Our final picture shows how this is done in one intance. In a wide in fully laid down, so that two double ranks of cars may be parked without interfering with the entrance or exit lines. This is economy of space carried to the last degree.

Racing with Model Yachts (Continued from page 511)

In the Regatta races boats sail according to class; but in the point races class is not taken into account. Prizes are given to the winners for the season.

The Prospect Park Model Yacht Club at present is made up of former members of the Brooklyn Model Yacht Club and the Yankee Model Yacht Club, who agreed to join into one organization for at least six months. This plan has worked out very well and will no doubt result in a permanent organization probably under the present name.

The enthusiasm of the yacht races is not confined to the older members of the club, the younger members being fully as expert yachtsmen. On the large course is five-eighths of a mile, and on the windward and leeward course the yachts sail a half-mile by covering their course twice. Some excellent scores have been made over this course. Thus the schooner "Fairwind" covered the triangular course in 12 minutes 55 seconds. The "Hilma" covered the same course in elapsed time 13 minutes, or 15 minutes 17 seconds by corrected time.

Quite a lively. sight is the start of one of these races when more than half-adozen of the yachts are jockeying for the best position to cross the line, while on the shore opposite the stake stands the timer with his watch and recording tablets, keeping accurate account of the time each one crosses.

Collisions happen frequently, but they are not usually serious, the damage being easily remedied. In a heavy wind the vachts heel over to an alarming degree, but thanks to their deep lead keels, always right themselves. So great is the speed of the large yachts that the owners frequently have to put in some hard rowing to keep up with the diminutive but fast-moving craft.

\section{Concerning Ice}

\section{(Continued from page 512 )}

tension. The problem of the strength of the piston did not prove of difficulty, for it was found that the compression supported by a piece of glass-hard steel held rigidly is surprisingly large. Several grades of steel were found which would support a compression of 600,000 pounds and one grade stood up under as much as 750,000 pounds per square inch.

No theory of the strength of a cylinder was of much value for very high pressures. It is of no use to make indefinitely thick walls, nor indeed to make them more than a certain thickness; for the inside layers support most of the pressure in any event. The outer layers of a very thick cylinder do not take up the stress from the inner layers. Dr. Bridgman concluded that the best way to make a cylinder support a high pressure was first to stretch it on the inside by applying a much higher pressure than it was intended

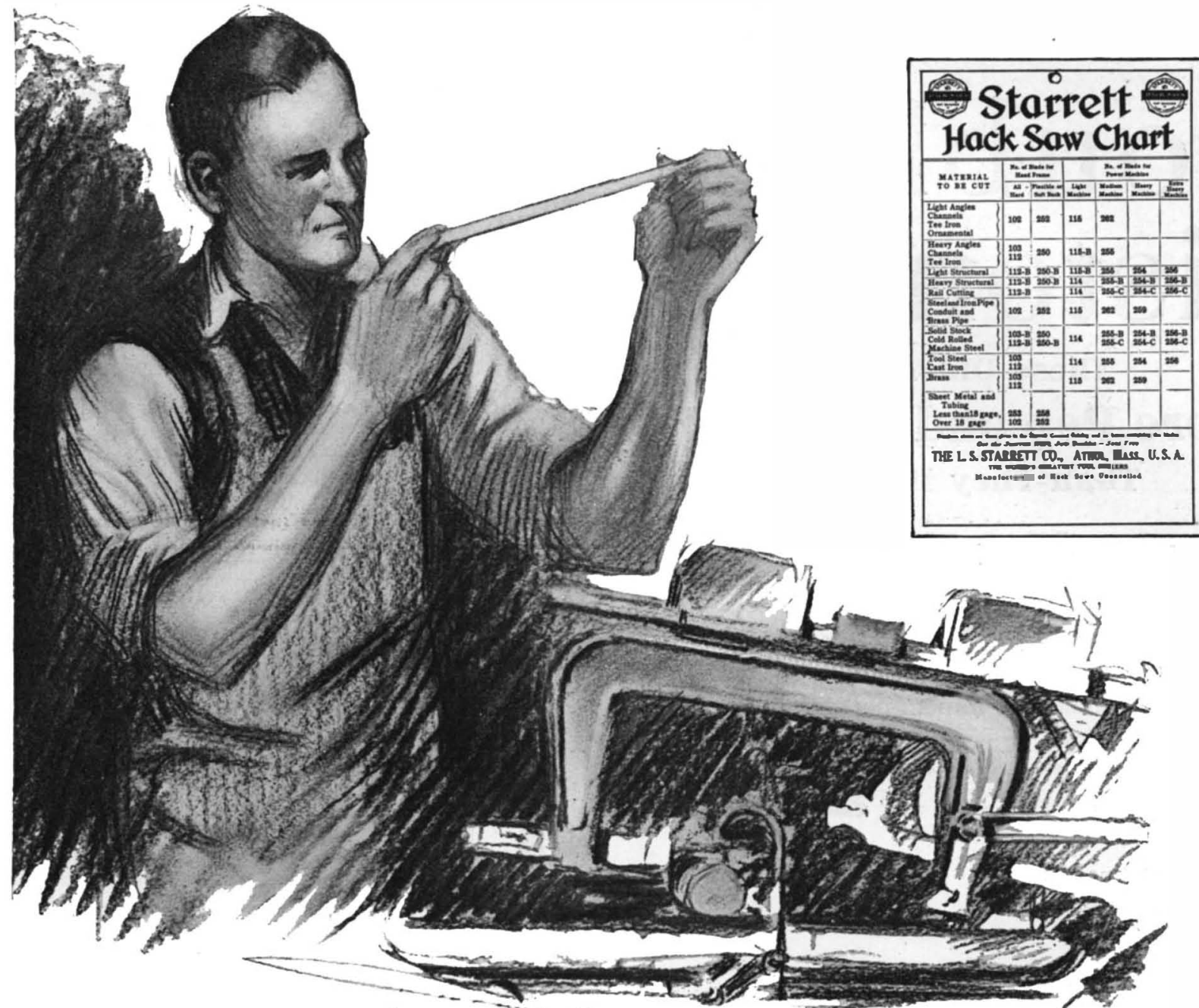

The gage of a blade directly affects its cutting speed.

Take two hacksaws, both suited to cutting some particular kind or shape of metal but differing only in the matter of gage. The thinner of the two will cut the quicker.

The contact area of the larger blade-the square area of the saw in actual contact with the work-means more friction to be overcome, and after the first few cuts, more weight upon the saw becomes necessary.

The Starrett Hacksaw Chart indicates the most efficient type of blades to use on any given kind of work. Starrett Saws, used according to it, give the best results.

Send for Catalog No. 22 "B"

\section{THE L. S. STARRETT COMPANY}

The World's Greatest Toolmakers Manufacturers of Hack Saws Unexcelled.

ATHOL; MASS.

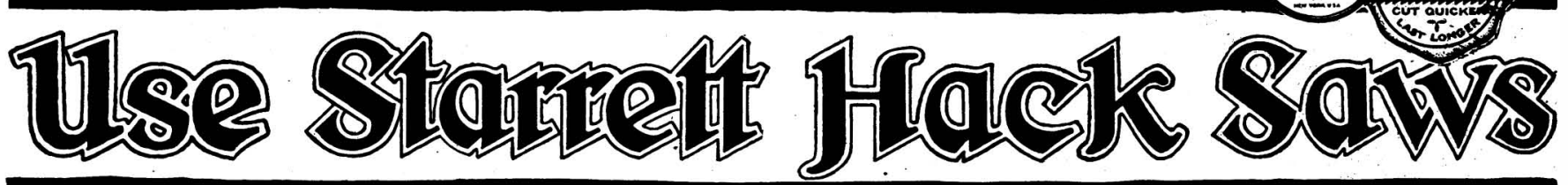

Attention to Details Essential to Efficiency

The necessity of increasing the weight as the saw is dulled must not be overlooked, and is a factor for which no absolute rule can be given. The most that can be said is, knowing approximately the time in which a certain blade should cut an average specimen of a certain kind and size of material, the weight should be increased by increments of from 5 to 10 pounds as often as the time of three successive cuts is above the average. Remember that the weight on a heavy gage saw must be increased faster, in proportion to the extra amount of dulled surface or contact area, than for a thinner gage saw, regardless of the difference in weights on the first cut with each. In Hack Sawing, as in any other form of work, common sense, attention to detail and observation of manufacturers' instructions are great assets.

To sum up: The attainment of real efficiency in cutting metals with either hand or power Hack Saws depends upon:

1. The selection of the proper make of saw.

2. The selection of the proper saw of that make for the material that is to that mat.

3. The proper use of the saw selected. 3. The proper use of the saw selected.
It is possible for any user of Hack
Saws, at the expense of time and money, to evolve for himself a system for selecting and using Hack Saws to the best advantage. It is likely there are many machinists whose experience is sufficiently wide to warrant their making their own selection of saws and establishing their own code of usage To this class of men this book will To this class of men, this book will have been but firmation of facts they already know. To the man who has not had the advantage of such wide experience, it is hoped that this book will prove of value in hi search for the means of more efficient work and methods.-From "Hack Saws and Their Use," published by The L. S.
Starrett Co., for free distribution. 